\title{
Coronary Artery Fistula and Its Imaging Modalities-A Review Article
}

\author{
Singh Shrestha Arati, Ji-Yang Jin* \\ Department of Radiology, Zhongda Hospital, School of Medicine, Southeast University, Nanjing, China \\ Email: *jy_jin@126.com
}

How to cite this paper: Arati, S.S. and Jin, J.-Y. (2017) Coronary Artery Fistula and Its Imaging Modalities-A Review Article. Open Journal of Radiology, 7, 121-129. https://doi.org/10.4236/ojrad.2017.72014

Received: April 12, 2017

Accepted: June 19, 2017

Published: June 22, 2017

Copyright $\odot 2017$ by authors and Scientific Research Publishing Inc. This work is licensed under the Creative Commons Attribution International License (CC BY 4.0).

http://creativecommons.org/licenses/by/4.0/

\begin{abstract}
Coronary artery fistula (CAF) is known be a rare defect of coronary artery. When there is an abnormal pre-capillary communication between single or multiple branches of the coronary artery and any of the cardiac chambers or great vessels, it is designated as CAF. It can be found in both congenital and acquired form. Congenital origin of fistula occupies higher percentage compared to the acquired one. A wide variety of imaging modalities have been lunched to provide the best possible way to access and treat the defect. With regard to the assessment of the coronary artery fistula, trans-thoracic Doppler echocardiography and multi-slice CT (MSCT) angiography have commendable role, however, MSCTA comes in the leading position.
\end{abstract}

\section{Keywords}

Coronary Artery Fistula, Doppler Echocardiography, Multi-Slice CT Angiography

\section{Background}

\subsection{Introduction}

CAF is defined as an abnormal pre-capillary communication between single or more branches of the coronary artery and any of the cardiac chambers or great vessels. It is occasional finding in adult and paediatric population, and is seldom present among neonates. Patients are usually asymptomatic in the initial periods of life, and clinical presentations are frequently manifested from the $3^{\text {rd }}$ decade of life [1]. There is no race or gender predisposition for CAF [2]. MSCT angiography is the most popular imaging technique which has high spatial resolution and provides better delineation of the cardiac anomaly. Nowadays, use of MSCTA is being successful to detect the cases of CAF more frequently than documented before. 


\subsection{Aim and Objective}

The main objective of this review article is to focus on the vital aspects of CAF and stress upon the use of MSCT angiography for better diagnosis and treatment.

\section{Methods}

A PubMed and Google searches for published articles between 2000-2016 were done using the keywords: coronary artery fistula and multislice computed tomography angiography. The relevant articles within this period were studied and included in this review article. Also, few articles before 2000, which were congruent were comprehended.

\subsection{Epidemiology}

In Unites States, coronary artery anomalies are found to be $0.3 \%-1.3 \%$ among the patients who had undergone diagnostic coronary angiography, and about $1 \%$ of the routine autopsy examination, and in $4 \%-15 \%$ of young individuals who experience sudden death [1]. CAF may be congenital or acquired in origin; congenital origin being in higher percentage [3]. Acquired CAF may be secondary to chest trauma, coronary angioplasty or bypass surgery, multiple myocardial biopsies in cardiac transplantation [4] [5], inflammation, atherosclerosis or collagen vascular disease [6].

The accountancy of CAF is about $0.2 \%-0.4 \%$ among congenital cardiac anomalies [7]. The prevalence of CAF is estimated to be approximately $0.002 \%$ in the general population, and occupies around $0.05 \%-0.25 \%$ of patients who undergo coronary angiography [8] [9] [10] [11].

In the recent study done among Chinese population, the prevalence of coronary pulmonary artery fistula (CPAF) was found to be $0.17 \%$, which is thought to be much higher than previously reported in literature [12]. Kim et al. [13] reported a $0.32 \%$ prevalence of CPAF, based on their finding of $17 \mathrm{CPAF}$ cases in 5372 patients. Yun et al. [14] reported $29 \mathrm{CPAF}$ cases in 6624 patients who underwent CTCA, resulting in an even higher prevalence of $0.44 \%$. Osama et al. [15] reported CAFs were seen in six patients which is $2.489 \%$ of all Coronary artery anomalies cases, and $0.2684 \%$ of all patients.

\subsection{Morphology}

The morphology of the fistula can be characterized by dilatation and tortuosity in most of the cases but not necessarily to be in all. The rising artery of the fistula is contributed from either the main coronary artery or its branches and is dissipated into either cardiac chamber or great vessels. The location of feeding artery and the host artery attribute to dilatation of the fistula. As the feeding artery lies more proximal in the main coronary artery, the more dilatation it causes [4].

Solitary communication of fistulae make greater evidence, however, multiplex fistulae are not to be denied. Multiplex fistulae may be put forward in two ways; 
I. Multiple origins with single terminal point. II. Multiple origins with multiple terminal points [4].

\subsection{Pathophysiology}

When a normal coronary artery is studied, the termination is described as broom-like arborisation, penetrating into the myocardium [16]. Normally the communications between coronary arteries with great vessels and cardiac chamber takes place through sinusoids; and on the course of development, these sinusoids transform into a normally calibrated capillary network. Congenital CAF are assumed to originate as the sequel of incomplete embryonic development. In case of fistula, primordial pericardial vessels share persistent junctions with intramyocardial sinusoidal circulation. The recipient location where the fistula drains is of ample attention. When the drainage site is right sided of heart, volume overload is augmented to right heart along with pulmonary vasculature, left atrium and left ventricle. On the contrary, when the left sided heart appears as drainage site, volume overload is augmented in left side without influencing the pulmonary blood flow. The dilatation of different cardiac chambers due to shunt is evident in echocardiography. The pressure difference between the host (coronary) artery and the recipient chamber and also the size of fistula determines the size of shunt. The left-to-right shunt was evident in over $90 \%$ cases [17].

The outbreak of CAF is mostly from right coronary artery (RCA), occupying approximately $50 \%$ of the patient, followed by the left coronary artery (LCA) $(42 \%)$, and both left and right coronary artery (LCA and RCA) constituting almost 5\% [18]. As identified with coronary angiogram, these fistulae are dissipated to most commonly right ventricles (RV) (41\%), followed by right atrium (RA) (26\%), pulmonary artery (PA) (17\%), coronary sinus (7\%), left atrium (LA) (5\%), left ventricle (LV) (3\%) and superior venacava (SVC) (1\%) [19].

\subsection{Clinical Features}

Clinical features usually remain silent till the first two decades of life, being small hemodynamically. After this period, symptoms are frequent with increased risk of complications [20]. The clinical scenario is principally ancillary on the severity of left-to-right shunt [17].

Studies establish continuous cardiac murmur to be the most common clinical presentation; however, there may be associated chest pain, chest distress, palpitation, syncope, dizziness, fatigue and orthopnea [21] [22]. If there exists ischemic symptoms, it is assumed to be due to coronary steal from the adjacent myocardium resulting in complications such as myocardial ischemia, thrombosis and embolism, cardiac failure, atrial fibrillation, endocarditis and arrhythmias [23] [24] [25] [26] [27]. In case of large left to right shunt, potential complications such as pulmonary hypertension, congestive cardiac failure, and ruptures or thrombosis of the fistula or associated arterial aneurysm [17] [22] may be resulted. 


\subsection{Diagnostic Modalities}

Various imaging modalities have been introduced aiming to access the fistula to display clear anatomic pictures. Electrocardiogram (ECG) and chest x-ray are done routinely, but they are found to have minimum benefit to ascertain the diagnosis. ECG may sometimes present ischaemic changes or effects of left ventricular volume overload but most of the times, it can be normal [22]. In general, chest X-ray also exhibits normal pattern. However, owing to RV hypertrophy or secondary ventricular hypertrophy due to large left to right shunt, mild to moderate cardiomegaly may be expressed. In few cases, marked abnormal shadow may be demonstrated [3] [28]. Role of echocardiography is commendable. Two dimensional and colour Doppler echocardiography plays vital role in illustrating the dilatation and aneurysm of the affected coronary artery and the dilatation of the recipient chamber. Sometimes it is difficult to deal with the detail anatomy. It may provide a clue if feeding artery is enlarged or tortuous. On colour Doppler flow imaging, large flow may be seen at the source, along the length of the vessel and the exit site [28]. Thrombotic and vascular masses have been visualised by echocardiography. A variety of associated congenital and acquired heart defects are illustrated in echocardiography, along with the calculation of left to right shunt and right sided pressure estimation [17]. In one of the studies, it is suggested that the trans-thoracic echocardiography by newer echo machine have substantial resolution to detect most significant fistula [3]. Hence, Doppler echocardiography has been proved to be of great diagnostic value in the detection, intra-operative imaging and follow up of the patient with CAF [29].

Conventional coronary angiography was popular before though expensive and invasive. To some extent, it can elucidate the source of CAF along with its size and number. However, these fistulas being dissipitated to low-pressure cardiac chamber and due to marked dilatation of contrast medium, the exit site may not be well visualized [30].

Magnetic Resonance (MR) imaging and CT are useful, non-invasive and accurate imaging techniques in dealing with coronary artery malformation. In the recent days, use of MSCT angiography is accelerating for displaying coronary anatomy. With respect to the problems encountered with invasiveness, well visualization of complex contour of the vessels and their relations with the surrounding anatomic structures, the need and demand of the MSCT angiography has increased. This technique is much faster than MR angiography and can be performed in single breath-hold. Further, for MR imaging, patient needs to be sedated augmenting the risk of complications. In addition, the spatial resolution of MR imaging is often limited. MSCT angiography allows the use of its multiplanar reformated (MPR) images and facilitates with high resolution anatomic image to exhibit the origin, course and drainage site of fistulas [30] [31] [32] [33]. The high quality images are produced with the use of ECG gated dual tube 256 slice CT which uses ECG gated image reconstruction algorithm allowing phase correlated image data sets [34].

As mentioned earlier, coronary to ventricular fistula was considered to be the 
most common type. However, some studies showed that the most common type is coronary to pulmonary artery fistula. In both these studies, MSCT angiography was done which assisted for the above findings [12] [35]. Many studies reported in the literature had proved MSCT as the best diagnostic tool.

\subsection{Management}

As most of the CAFs are asymptomatic, closure of fistula is not an urgent option. Treatment of CAF may range from medical to surgical management. However, periodic evaluation and follow up is crucial in either of the cases [22]. Medical management may include anti-platelet therapy and prophylactic precautions against bacterial endocarditis. Another non-surgical option is trans-catheter embolization of the fistulous connection [17] [22]. If CAF is large, it is recommended for surgical intervention however, surgery is not risk free. Concern must be given for the post-operative complications such as post-operative recanalization, dilatation of coronary artery and ostium persistently, thrombus formation, calcification, arrhythmias and myocardial infarction [17].

\subsection{Discussion}

Defined as subtle vascular anomalies between coronary artery and other cardiac structure, CAF is rarely accounted and few numbers of cases have been mentioned in literature. With respect to the source and exit site, CAF can be classified into 2 types: 1) fistula from coronary to cardiac chamber (Figure 1); 2) fistula from coronary to pulmonary vessels (Figure 2). It is assumed to be due to the fact that the cases detected incidentally during coronary artery evaluation by MDCT were abundant. The possibility for the variation in prevalence among different populations may be due to ethnic differences, and also the retrospective nature of the studies which may miss some small CPAF contribute to the differences in prevalence [12]. Most of the times, literature alludes fistula arising from RCA to be dominant. However, certain studies had also demonstrated both from RCA and LCA to be equal [8] [36] [37]. Majority of cases are incidental findings on the course of investigation secondary to other disease, hence, the clinical

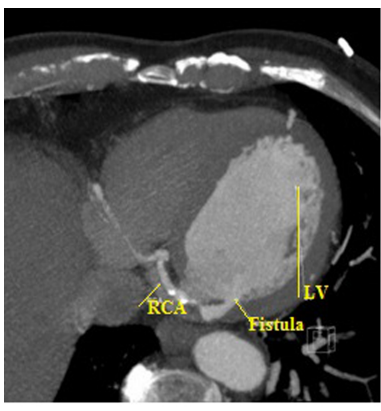

(a)

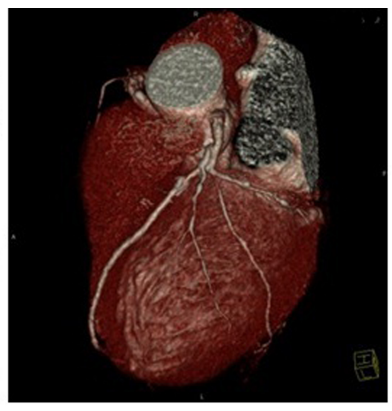

(b)

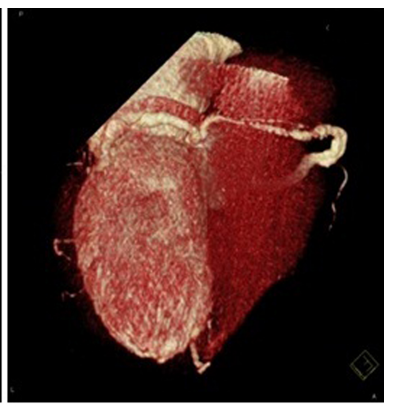

(c)

Figure 1. Coronary to cardiac chamber. 64 years male with CAF rising from RCA and draining to LV. MS-CTA [Image (a) is Maximum Intensity Projection, (b) and (c) are Volume Rendering images] displaying dilated, tortuous vascular pathway (arrow) arising from RCA and terminating to LV along with multiple calcifications. 


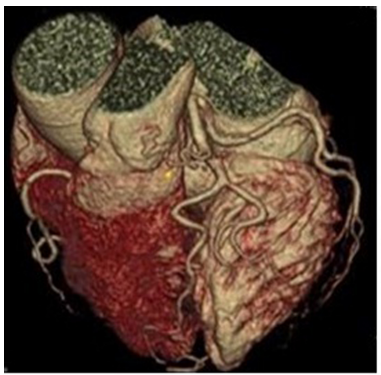

(a)

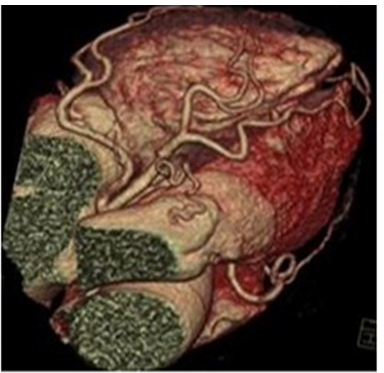

(b)

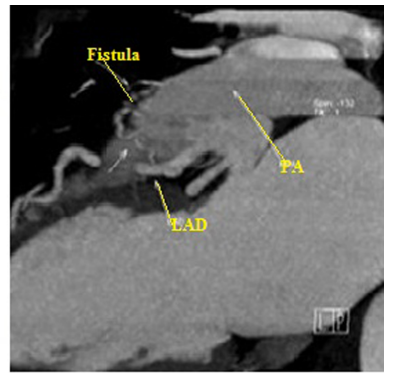

(c)

Figure 2. Coronary to pulmonary vessels. Case of 63 years female with CAF originating from LAD and draining to PA. MS-CTA [Image (a), (b) display Volume Rendering image, Image (c) displays Maximum Intensity Projection]; These images display tortuous vascular pathway (arrows) arising from inner wall of proximal LAD, leading forward and terminating in PA.

presentations cannot be particularized. Discrete applied science has bestowed discrete privilege to aid the diagnosis of CAF. Doppler echocardiography is also a proper non-invasive way to identify CAF along with their courses. However, among all, contrast enhanced MSCT angiography is a promising non-invasive three-dimensional (3D) imaging modality that provides commendable overview of the cardiac and surrounding vascular anatomy. Various sequences such as axial image, volume rendered 3D reconstruction, curved MPR images, maximum intensity projection images not only furnish diagnostic aid, but also help for planning future therapeutic approach, interventional or surgical. The major limitation of MSCT angiography is the radiation exposure, however, the promising therapeutic enhancement predominates this risk. The management should be individualised according to the configuration of CAF and keeping in mind the possible outcome of any therapy.

\section{Conclusion}

CAF is considered to be rare. But, to our surprise, with the advent use of MSCT angiography, the cases of CAF are found to be frequent thus increasing the prevalent rate than documented before. In the same manner, the earlier accounted origin and drainage site have also been changed. This is all possible due to the wide use of MSCT angiography which leads to the accurate diagnosis and assist in further therapeutic action. Thus clinicians opt the use of MSCT angiography.

\section{Compliance}

Compliance with Ethical Standards.

\section{Conflict of Interest}

None.

\section{Funding}

There is no funding source. 


\section{Ethical Approval}

This article does not contain any studies with human participants or animals performed by any of the authors.

\section{References}

[1] Shirani, J., Brofferio, A., Talavera, F., Compton, S. and Suleman, A. (2008) Isolated Coronary Artery Anomalies.

[2] Pelech, A. (2012) Coronary Artery Fistula. Available from: eMedicine com/PED/ Topic, 2505.

[3] Chiu, S.N., Wu, M.H., Lin, M.T., Wu, E.T., Wang, J.K. and Lue, H.C. (2005) Acquired Coronary Artery Fistula after Open Heart Surgery for Congenital Heart Disease. International Journal of Cardiology, 103, 187-192.

https://doi.org/10.1016/j.ijcard.2004.09.005

[4] Reidy, J.F., Anjos, R.T., Qureshi, S.A., Baker, E.J. and Tynan, M.J. (1991) Transcatheter Embolization in the Treatment of Coronary Artery Fistulas. Journal of the American College of Cardiology, 18, 187-192.

https://doi.org/10.1016/S0735-1097(10)80239-6

[5] Somers, J.M. and Verney, G.I. (1991) Coronary Cameral Fistulae Following Heart Transplantation. Clinical Radiology, 44, 419-421.

https://doi.org/10.1016/S0009-9260(05)80664-6

[6] Abe, T., Kamata, K., Nakanishi, K., Morishita, K. and Komatsu, S. (1996) Successful Repair of Coronary Artery-Coronary Sinus Fistula with Aneurysm in an Adult. The Annals of Thoracic Surgery, 61, 1520-1523.

https://doi.org/10.1016/0003-4975(96)80001-R

[7] Chen, C.C., Hwang, B., Hsiung, M.C., Chiang, B.N., Meng, L.C., Wang, D.J. and Wang, S.P. (1984) Recognition of Coronary Arterial Fistula by Doppler 2-Dimensional Echocardiography. The American Journal of Cardiology, 53, 392-394.

https://doi.org/10.1016/0002-9149(84)90489-2

[8] Barbosa, M.M., Katina, T., Oliveira, H.G., Neuenschwander, F.E. and Oliveira, E.C. (1999) Doppler Echocardiographic Features of Coronary Artery Fistula: Report of 8 Cases. Journal of the American Society of Echocardiography, 12, 149-154. https://doi.org/10.1016/S0894-7317(99)70127-6

[9] Balanescu, S., Sangiorgi, G., Castelvecchio, S., Medda, M. and Inglese, L. (2001) Coronary Artery Fistulas: Clinical Consequences and Methods of Closure. A Literature Review. Italian Heart Journal, 2, 669-676.

[10] Kamineni, R., Butman, S.M., Rockow, J.P. and Zamora, R. (2004) An Unusual Case of an Accessory Coronary Artery to Pulmonary Artery Fistula: Successful Closure with Transcatheter Coil Embolization. Journal of Interventional Cardiology, 17, 5963. https://doi.org/10.1111/j.1540-8183.2004.01711.x

[11] Athanasias, D.A., Van Ommen, V. and Bar, F. (2002) Coronary Artery-Pulmonary Artery Fistula Originating from the Left Anterior Descending Artery: A Case Report and Literature Review. Hellenic Journal of Cardiology, 43, 78-81.

[12] Zhang, L.J., Zhou, C.S., Wang, Y., Jin, Z., Yu, W., Zhang, Z., Zhang, B., Fang, X., Cui, X., Li, K., Huang, W., Zheng, L., Ji, X.M., Hoffman, C., Schoepf, U.J. and Lu, G.M. (2014) Prevalence and Types of Coronary to Pulmonary Artery Fistula in a Chinese Population at Dual-Source CT Coronary Angiography. Acta Radiologica, 55, 1031-1039. https://doi.org/10.1177/0284185113512299

[13] Kim, M.S., Jung, J.I. and Chun, H.J. (2010) Coronary to Pulmonary Artery Fistula: 
Morphologic Features at Multidetector CT. The International Journal of Cardiovascular Imaging, 26, 273-280. https://doi.org/10.1007/s10554-010-9711-3

[14] Yun, H., Zeng, M.S., Yang, S., Jin, H. and Yang, X. (2011) Congenital Coronary Artery Fistulas: Dual-Source CT Findings from Consecutive 6, 624 Patients with Suspected or Confirmed Coronary Artery Disease. Chinese Medical Journal, 124, 41724177.

[15] Smettei, O.A., Sayed, S. and Abazid, R.M. (2017) The Prevalence of Coronary Artery Anomalies in Qassim Province Detected by Cardiac Computed Tomography Angiography. Journal of the Saudi Heart Association, 29, 84-89. https://doi.org/10.1016/j.jsha.2016.07.006

[16] Schumacher, G., Roithmaier, A., Lorenz, H.P., Meisner, H., Sauer, U., Muller, K.D., Sebening, F. and Buhlmeyer, K. (1997) Congenital Coronary Artery Fistula In Infancy and Childhood: Diagnostic and Therapeutic Aspects. The Thoracic and Cardiovascular Surgeon, 45, 287-294. https://doi.org/10.1055/s-2007-1013751

[17] Gowda, R.M., Vasavada, B.C. and Khan, I.A. (2006) Coronary Artery Fistulas: Clinical and Therapeutic Considerations. International Journal of Cardiology, 107, 7-10. https://doi.org/10.1016/j.ijcard.2005.01.067

[18] Nakamura, M., Matsuoka, H., Kawakami, H., Komatsu, J., Itou, T., Higashino, H., Kido, T. and Mochizuki, T. (2006) Giant Congenital Coronary Artery Fistula to Left Brachial Vein Clearly Detected by Multidetector Computed Tomography. Circulation Journal: Official Journal of the Japanese Circulation Society, 70, 796-799. https://doi.org/10.1253/circj.70.796

[19] Lin, F.C., Chang, H.J., Chern, M.S., Wen, M.S., Yeh, S.J. and Wu, D. (1995) Multiplane Transesophageal Echocardiography in the Diagnosis of Congenital Coronary Artery Fistula. American Heart Journal, 130, 1236-1244. https://doi.org/10.1016/0002-8703(95)90148-5

[20] Liberthson, R.R., Sagar, K., Berkoben, J.P., Weintraub, R.M. and Levine, F.H. (1979) Congenital Coronary arteriovenous Fistula. Report of 13 Patients, Review of the Literature and Delineation of Management. Circulation, 59, 849-854. https://doi.org/10.1161/01.CIR.59.5.849

[21] Okwuosa, T.M., Gundeck, E.L. and Ward, R.P. (2006) Coronary to Pulmonary Artery Fistula-Diagnosis by Transesophageal Echocardiography. Echocardiography, 23, 62-64. https://doi.org/10.1111/j.1540-8175.2006.00116.x

[22] Said, S.A., Lam, J. and van der Werf, T. (2006) Solitary Coronary Artery Fistulas: A Congenital Anomaly in Children and Adults. A Contemporary Review. Congenital Heart Disease, 1, 63-76. https://doi.org/10.1111/j.1747-0803.2006.00012.x

[23] Wilde, P. and Watt, I. (1980) Congenital Coronary Artery Fistulae: Six New Cases with a Collective Review. Clinical Radiology, 31, 301-311. https://doi.org/10.1016/S0009-9260(80)80223-6

[24] McNamara, J.J. and Gross, R.E. (1969) Congenital Coronary Artery Fistula. Surgery, 65, 59-69.

[25] Alkhulaifi, A.M., Horner, S.M., Pugsley, W.B. and Swanton, R.H. (1995) Coronary Artery Fistulas Presenting with Bacterial Endocarditis. The Annals of Thoracic Surgery, 60, 202-204. https://doi.org/10.1016/S0003-4975(95)00037-2

[26] Skimming, J.W. and Walls, J.T. (1993) Congenital Coronary Artery Fistula Suggesting a "Steal Phenomenon" in a Neonate. Pediatric Cardiology, 14, 174-175. https://doi.org/10.1007/BF00795649

[27] Oshiro, K., Shimabukuro, M., Nakada, Y., Chibana, T., Yoshida, H., Nagamine, F., Sunagawa, R., Gushiken, M., Murakami, K. and Mimura, G. (1990) Multiple Coro- 
nary LV Fistulas: Demonstration of Coronary Steal Phenomenon by Stress Thallium Scintigraphy and Exercise Hemodynamics. American Heart Journal, 120, 217-219. https://doi.org/10.1016/0002-8703(90)90185-Z

[28] Qureshi, S.A. (2006) Coronary Arterial Fistulas. Orphanet Journal of Rare Diseases, 1, 51. https://doi.org/10.1186/1750-1172-1-51

[29] Abdelmoneim, S.S., Mookadam, F., Moustafa, S.E. and Holmes, D.R. (2007) Coronary Artery Fistula with Anomalous Coronary Artery Origin: A Case Report. Journal of the American Society of Echocardiography: Official Publication of the American Society of Echocardiography, 20, 333.e1-333.e4. https://doi.org/10.1016/j.echo.2006.09.012

[30] Schmitt, R., Froehner, S., Brunn, J., Wagner, M., Brunner, H., Cherevatyy, O., Gietzen, F., Christopoulos, G., Kerber, S. and Fellner, F. (2005) Congenital Anomalies of the Coronary Arteries: Imaging with Contrast-Enhanced, Multidetector Computed Tomography. European Radiology, 15, 1110-1121. https://doi.org/10.1007/s00330-005-2707-Z

[31] Taoka, Y., Nomura, M., Harada, M., Mitani, T., Endo, J., Kondo, Y., Yukinaka, M., Ito, S., Nakaya, Y. and Nishitani, H. (1998) Coronary-Pulmonary Artery Fistulae Depicted by Multiplanar Reconstruction Using Magnetic Resonance Imaging. Japanese Circulation Journal, 62, 455-457.

[32] Kacmaz, F., Ozbulbul, N.I., Alyan, O., Maden, O., Demir, A.D., Balbay, Y., Erbay, A.R., Atak, R., Senen, K., Olcer, T. and Ilkay, E. (2008) Imaging of Coronary Artery Anomalies: The Role of Multidetector Computed Tomography. Coronary Artery Disease, 19, 203-209. https://doi.org/10.1097/MCA.0b013e3282f528f1

[33] Chang, D.S., Lee, M.H., Lee, H.Y. and Barack, B.M. (2005) MDCT of Left Anterior Descending Coronary Artery to Main Pulmonary Artery Fistula. AJR American Journal of Roentgenology, 185, 1258-1260. https://doi.org/10.2214/AJR.04.1415

[34] Schroeder, S., Achenbach, S., Bengel, F., Burgstahler, C., Cademartiri, F., de Feyter, P., George, R., Kaufmann, P., Kopp, A.F., Knuuti, J., Ropers, D., Schuijf, J., Tops, L.F. and Bax, J.J. (2008) Cardiac Computed Tomography: Indications, Applications, Limitations, and Training Requirements: Report of a Writing Group Deployed by the Working Group Nuclear Cardiology and Cardiac CT of the European Society of Cardiology and the European Council of Nuclear Cardiology. European Heart Journal, 29, 531-556. https://doi.org/10.1093/eurheartj/ehm544

[35] Lim, J.J., Jung, J.I., Lee, B.Y. and Lee, H.G. (2014) Prevalence and Types of Coronary Artery Fistulas Detected with Coronary CT Angiography. AJR American Journal of Roentgenology, 203, W237-W243.

https://doi.org/10.2214/AJR.13.11613

[36] Malekahmadi, M. and Shahmohammadi, A. (2005) Surgical Outcome of Coronary Artery Fistulas Repair in Children. Pediatric Cardiology, 26, 328-330. https://doi.org/10.1007/s00246-004-0656-y

[37] Wong, K.T. and Menahem, S. (2000) Coronary Arterial Fistulas in Childhood. Cardiology in the Young, 10, 15-20. https://doi.org/10.1017/S1047951100006326 
Submit or recommend next manuscript to SCIRP and we will provide best service for you:

Accepting pre-submission inquiries through Email, Facebook, LinkedIn, Twitter, etc. A wide selection of journals (inclusive of 9 subjects, more than 200 journals)

Providing 24-hour high-quality service

User-friendly online submission system

Fair and swift peer-review system

Efficient typesetting and proofreading procedure

Display of the result of downloads and visits, as well as the number of cited articles Maximum dissemination of your research work

Submit your manuscript at: http://papersubmission.scirp.org/

Or contact ojrad@scirp.org 